\title{
Assessment of aortocoronary bypass grafting using exercise ST segment/heart rate relation
}

\author{
M M KARDASH, R M BOYLE, D A WATSON, J B STOKER, D A S G MARY, R J LINDEN \\ From the Department of Cardiovascular Studies, University of Leeds, and Killingbeck Hospital, Leeds
}

SUMMARY The maximal rate of progression of ST segment depression relative to increases in heart rate (maximal ST/HR slope) has recently been shown to be an accurate index of the presence and the severity of coronary heart disease in patients with angina. The value of this new exercise test was assessed in patients undergoing aortocoronary bypass.

The maximal ST/HR slope and the results of coronary angiography were obtained in each of 46 patients before aortocoronary bypass surgery and in 26 of the 46 patients six months after the operation. At each stage of the investigation the maximal ST/HR slope detected without false results the absence and the number of significantly diseased vessels as shown by angiocardiography. As in previous findings the ranges of the maximal ST/HR slope showed no overlap between the four groups of patients: those with no significant disease and those with single, double, or triple vessel disease. In each of the 46 patients in whom the maximal ST/HR slope was determined before operation and three months afterwards the slope was lower after operation than before, indicating improvement. Follow up examinations showed that the maximal ST/HR slopes accurately detected the number of patent grafts used to bypass significantly diseased coronary arteries. Furthermore, the development of a significant narrowing or occlusion in any vein graft caused an increase in the maximal ST/HR slope which was equivalent to the value of single vessel disease.

It is suggested that the maximal ST/HR slope may be used reliably in individual patients to indicate restoration of adequate blood supply to the myocardium after successful aortocoronary bypass surgery and to detect in the period of six months after the operation the degree of severity of coronary heart disease whether it is caused by occlusion of the graft or significant disease of the coronary arteries.

A new non-invasive exercise test has been developed in which the maximal rate of progression of ST segment depression relative to increases in heart rate during exercise (the maximal ST/HR slope) was used as an index of ischaemia, particularly in coronary heart disease. ${ }^{2}$ Several trials have shown that the maximal ST/HR slope can be used accurately to detect the presence or absence and the severity of coronary heart disease in individual patients with angina; a brief review which included data from 230 patients has been published. ${ }^{3}$

In the present study the use of the new test was extended to patients undergoing aortocoronary bypass surgery in an attempt to detect improvement in coro-

Requests for reprints to Professor R J Linden, Department of Cardiovascular Studies, University of Leeds, Leeds LS2 9JT.

Accepted for publication 18 October 1983 nary blood supply or any obstruction in the vein graft. The results obtained using the new test were compared with those of coronary arteriography independently assessed.

\section{Patients and methods}

Forty six consecutive patients who presented with angina pectoris and were referred for exercise studies before and after aortocoronary bypass surgery were included in the present study. Of the patients considered for the study, none was unable to complete the exercise test. For the purpose of the present study the exclusion criteria used at the various stages of selection of the patients were as follows. At the stage of consultancy by the clinical consultant and before referral for the exercise test patients with hypertension, heart failure, cardiac arrhythmias, and valve dis- 
ease were excluded from the trial as were patients taking digoxin or calcium antagonists. A decision was also made to exclude patients subsequently shown to have a left ventricular aneurysm evident on left ventriculography. Patients taking beta blocking drugs were not excluded from the study since beta blockade does not affect the maximal ST/HR slope. ${ }^{4}$ At the stage of referral for coronary arteriography patients who had responded to medical treatment were excluded. At the stage of referral for aortocoronary bypass surgery patients in whom the lesions defined by coronary arteriography were considered by the cardiac surgeon to be unsuitable for any operative intervention were excluded. After surgery only survivors could be considered for the study, and no other selection criteria excluded patients from consideration for postoperative exercise test and angiocardiography. Throughout these stages, patients were not excluded on the basis of residual electrocardiographic evidence of myocardial infarction either before or after surgery.

\section{EXERCISE TEST}

The exercise test was performed before aortocoronary bypass surgery and at least twice afterwards, at three and six months. The results were analysed without knowledge of the angiographic findings or details of the surgical procedure. The patients attended the laboratory at least two hours after the last meal and were exercised in the upright position on an electrically braked bicycle ergometer (Elema Schonander, type 380); the protocol has been reported in detail. ${ }^{2}$

Briefly, in each patient the test was preceded by a recording of the resting electrocardiogram in the supine and upright positions before and during hyperventilation and during a short preliminary exercise to determine the step increases in workload necessary to obtain step increases in heart rate of about 10 beats/min. After a suitable rest period (heart rate down to within $5 \%$ of previous control) the workload was increased in these steps at three minute intervals. The test was terminated for any of the following reasons: presence of anginal pain, occurrence of severe ST depression (more than $0.3 \mathrm{mV}$ ), an incidence of more than six multifocal ventricular extrasystoles, tachyarrhythmias, a decrease in blood pressure, or exhaustion of the patient.

The electrocardiogram was recorded from 13 leads - 12 conventional leads and a bipolar lead (CM5)—using an ink jet recorder (Mingograph 62; Siemens) as described ${ }^{12}$ and calibrated in the usual manner; a $1 \mathrm{mV}$ signal caused a displacement of 10 $\mathrm{mm}$. Records were obtained at a paper speed of 25 $\mathrm{mm} / \mathrm{s}$ for each lead before exercise, during the last minute of each exercise step, and for at least five minutes after cessation of exercise. The electrocardiogram was monitored continuously during the test, and the systolic blood pressure measured during the last minute of each step as well as before and after exercise. ${ }^{12}$ The values for heart rate and ST displacement used in this study were taken as the mean of values measured in at least 10 consecutive cardiac cycles and were obtained from the records of all 13 leads. The displacement of the ST segment was measured at a point $80 \mathrm{~ms}$ after the end of the QRS complex; a line drawn in each cardiac cycle between consecutive PR segments was taken as zero reference for the measurement of ST segment displacement.

Using the values of the depression of the ST segment below the zero reference and the heart rate during exercise the maximal ST/HR slope was derived as previously described. ${ }^{2}$ This slope represents the steepest slope of all the regression lines which show a linear relation (between the heart rate and depression of the ST segment) obtained from the 13 leads. The maximal ST/HR slope thus indicates in each patient the maximal rate of development of ST segment depression with respect to the increase in heart rate during exercise and has the units $\mathrm{mm}$. beats ${ }^{-1}$. min. $10^{-3}$.

\section{ANGIOCARDIOGRAPHY}

Coronary arteriography and left ventriculography were performed in the usual manner before operation. These procedures were repeated six months postoperatively as part of the ongoing examination of patients undergoing aortocoronary bypass surgery. In all the patients in whom comparisons between the results of angiocardiography and the exercise test were made, whether in the preoperative or the postoperative period, the exercise test was performed within one week of angiocardiography. The results of angiocardiography were assessed and documented without knowledge of the results of the exercise test.

\section{Classification of patients}

Narrowing of the coronary artery was assessed as previously described ${ }^{12}$; significant coronary artery disease was defined as $>75 \%$ luminal narrowing in the diameter of the artery. ${ }^{2}$ The narrowing of any lesion of a major coronary artery was estimated at its narrowest point and expressed as a percentage of the proximal segment of the vessel considered to be normal or least affected with disease. Narrowing of the aortocoronary bypass graft was assessed as the percentage reduction in the diameter of the stenosed part relative to the diameter of the nearest normal segment; narrowing of $75-100 \%$-that is, narrowing $>75 \%$-in diameter was considered significant. Using such definitions the patients were classified angiographically through joint assessments by the cardiologists (JBS, RMB) and the radiologists. Percentage narrowing was assessed by visual impression of the lesions 
Table 1 Clinical and angiocardiographic details in the preoperative period in 46 patients

\begin{tabular}{|c|c|c|c|c|c|c|}
\hline \multirow{2}{*}{$\begin{array}{l}\text { Coronary artery } \\
\text { disease }\end{array}$} & \multicolumn{2}{|c|}{ No of patients } & \multicolumn{2}{|l|}{ Age (y) } & \multirow[t]{2}{*}{ History of $M I^{\star}$} & \multirow{2}{*}{$\begin{array}{l}\text { Hypokinesia of left } \\
\text { ventricle }\end{array}$} \\
\hline & $M$ & $F$ & Range & Mean $\pm S D$ & & \\
\hline $\begin{array}{l}\text { Single vessel } \\
\text { Double vessel } \\
\text { Triple vessel }\end{array}$ & $\begin{array}{r}9 \\
22 \\
13\end{array}$ & $\frac{-}{2}$ & $\begin{array}{l}37 \cdot 0-56 \cdot 0 \\
44 \cdot 0-61 \cdot 0 \\
31 \cdot 0-63 \cdot 0\end{array}$ & $\begin{array}{l}50 \cdot 4 \pm 6 \cdot 56 \\
50 \cdot 0 \pm 4.76 \\
48 \cdot 9 \pm 7 \cdot 27\end{array}$ & $\begin{array}{l}2 \\
3 \\
3\end{array}$ & $\begin{array}{l}2 \\
6 \\
8\end{array}$ \\
\hline
\end{tabular}

$\star$ None of the patients had sustained myocardial infarction (MI) within six months before operation.

based on the maximal severity in any one of the views obtained. The following planes were used: for the left coronary system the planes were lateral, $40^{\circ}$ left anterior oblique, $15^{\circ}$ right anterior oblique, $40^{\circ}$ right anterior oblique, and left anterior oblique with craniocaudal tilt; for the right coronary artery the planes were $40^{\circ}$ left anterior oblique, $15^{\circ}$ right anterior oblique, and $40^{\circ}$ right anterior oblique. When there was still doubt about the definition of the lesion further planes were used-for example right anterior oblique with cephalocaudal tilt for lesions in the circumflex artery.

Preoperatively, the patients were divided into three groups with significant coronary artery disease: those with single, double, and triple vessel disease. Postoperatively, the patients were classified into four groups according to whether the vessels-the coronary artery or bypass graft-were significantly narrowed. The term significantly narrowed vessels was used to describe the presence of a significantly stenosed bypass graft or a significantly diseased coronary artery which remained ungrafted. Therefore, firstly, patients with no significant stenosis of the graft or the coronary arteries whether grafted or ungrafted were considered to have no significant vessel disease. Secondly, patients with one significantly diseased coronary artery or a bypass graft were considered to have single vessel disease. Finally, patients with more than one significantly diseased graft or significantly diseased artery or both were classified into those with double or triple vessel disease.

The above angiographic classifications were used because of previous findings showing that the adjacent ranges of the maximal ST/HR slopes in groups of patients with insignificant, single, double, or triple vessel disease showed no overlap. ${ }^{1-3}$

\section{SURGICAL TECHNIQUE}

The surgical technique used was identical in all the patients and included extracorporeal circulation, saphenous vein grafting, and closure of the pericardium. All the patients were managed by the same surgical team. In some patients a significantly diseased circumflex coronary artery was not grafted for technical reasons.

\section{Results}

Forty six patients who underwent aortocoronary bypass surgery for coronary artery disease were investigated. In 26 of these 46 patients repeat angiocardiography was performed six months after operation. In the remaining 20 of the 46 patients repeat angiocardiography after operation was not performed for the following reasons: seven patients refused postoperative angiocardiography; three were not restudied because of severe peripheral vascular disease, since a further arterial puncture might have proved hazardous; and 10 have not yet been considered for repeat angiocardiographic studies.

\section{CLINICAL AND ANGIOCARDIOGRAPHIC DETAILS}

The clinical and angiocardiography data of the 46 patients before operation are shown in Table 1. Of these 46 patients, 17 had no additional coronary lesions; the remainder (29 patients) had a maximal reduction in the lumen of vessels of - other than those with significant stenosis- $41.2 \%$ (mean; range 20 $60 \%$ ). In each of the 46 patients at least one significantly diseased coronary artery was bypassed; a total of 84 grafts was inserted. One of the 46 patients developed perioperative myocardial infarction.

In 26 of the 46 patients repeat angiocardiography

Table 2 Results of coronary angiography in 26 patients studied six months after aortocoronary bypass surgery

\begin{tabular}{|c|c|c|c|c|c|c|c|}
\hline \multirow[t]{3}{*}{ Group } & \multirow{3}{*}{$\begin{array}{l}\text { No of } \\
\text { patients }\end{array}$} & \multicolumn{2}{|c|}{ Ungrafted significantly diseased arteries } & \multicolumn{4}{|c|}{ Significantly stenosed vein.grafts } \\
\hline & & \multirow{2}{*}{$\begin{array}{l}\text { No of } \\
\text { arteries }\end{array}$} & \multirow{2}{*}{$\begin{array}{l}\text { Range (mean) of \% } \\
\text { narrowing }\end{array}$} & \multicolumn{2}{|c|}{ Total occlusion } & \multicolumn{2}{|c|}{ "Subtotal" significant stenosis } \\
\hline & & & & $\begin{array}{l}\text { No of } \\
\text { grafts }\end{array}$ & $\begin{array}{l}\% \\
\text { narrowing }\end{array}$ & $\begin{array}{l}\text { No of } \\
\text { grafis }\end{array}$ & $\begin{array}{l}\text { Range (mean) of } \\
\% \text { narrowing }\end{array}$ \\
\hline $\begin{array}{l}\text { No significant disease } \\
\text { Single vessel disease } \\
\text { Double vessel disease }\end{array}$ & $\begin{array}{r}8 \\
16 \\
2\end{array}$ & $\frac{-}{6}$ & $\overline{75}-100(82.5)$ & $\begin{array}{l}\overline{5} \\
3\end{array}$ & $\begin{array}{l}\overline{100} \\
100\end{array}$ & $\begin{array}{l}\overline{5} \\
1\end{array}$ & $\overline{75}-80(77)$ \\
\hline
\end{tabular}


Table 3 Maximal ST/HR slope (mm. beats $\left.{ }^{-1} \cdot \min .10^{-3}\right)$ in relation to the number of significantly diseased coronary vessels in 46 patients before aortocoronary bypass and in 26 of the 46 patients six months after operation

\begin{tabular}{|c|c|c|c|c|c|c|}
\hline \multirow[t]{3}{*}{ Group } & \multicolumn{3}{|c|}{ Before bypass } & \multicolumn{3}{|c|}{ After bypass } \\
\hline & \multirow{2}{*}{$\begin{array}{l}\text { No of } \\
\text { patients }\end{array}$} & \multicolumn{2}{|c|}{ Maximal ST/HR slope } & \multirow{2}{*}{$\begin{array}{l}\text { No of } \\
\text { patients }\end{array}$} & \multicolumn{2}{|c|}{ Maximal ST/HR slope } \\
\hline & & Range & Mean $\pm S D$ & & Range & Mean $\pm S D$ \\
\hline $\begin{array}{l}\text { No significant disease } \\
\text { Single vessel disease } \\
\text { Double vessel disease } \\
\text { Triple vessel disease }\end{array}$ & $\begin{array}{r}-9 \\
24 \\
13\end{array}$ & $\begin{array}{l}\overline{13} \cdot 0-21 \cdot 0 \\
33 \cdot 0-52 \cdot 0 \\
71 \cdot 0-119 \cdot 0\end{array}$ & $\begin{array}{l}\overline{17} \cdot 5 \pm 2 \cdot 69 \\
41 \cdot 9 \pm 6 \cdot 21 \\
89 \cdot 1 \pm 16 \cdot 75\end{array}$ & $\begin{array}{r}8 \\
16 \\
2 \\
-\end{array}$ & $\begin{array}{l}7 \cdot 0-11 \cdot 0 \\
15 \cdot 0-21 \cdot 0 \\
33 \cdot 0-39 \cdot 0 \\
-\end{array}$ & $\begin{array}{l}8.5 \pm 1.59 \\
18.9 \pm 1.88 \\
- \\
-\end{array}$ \\
\hline
\end{tabular}

was performed six months after aortocoronary bypass; the results are shown in Table 2 . In the 26 patients 49 vein grafts were used, and none of the patients developed perioperative myocardial infarction as assessed by serial 12 lead electrocardiography at rest. At six months after the operation 14 of the $49(28.6 \%)$ vein grafts used in the 26 patients were significantly stenosed. Progressive reduction in the diameter of the lumen of the coronary arteries over the period of six months did not exceed $20 \%$, and in none of the patients did this progression in coronary artery disease result in a narrowing $\geqslant 75 \%$. Mild to moderate hypokinesis of the left ventricle was found in five patients in the postoperative period.

Of the 26 patients, eight had no significant vessel disease (Table 2), and the maximal narrowing in any coronary artery was only $35 \%$ (mean; range $0-50 \%$ ). Five patients had one vein graft each, two patients had two grafts, and one patient had three vein grafts; all the 12 vein grafts were patent and the maximal stenosis in any of these 12 grafts averaged only $33.3 \%$ (range 0-50\%).

A further 16 of the 26 patients had single vessel disease (Table 2). There was one significantly diseased coronary artery which remained ungrafted in each of six patients and one significantly narrowed vein graft in each of the other 10 patients (Table 2); the narrowing of the vein grafts averaged $88 \%$ (range $75-100 \%$ ). Of the 26 patients the remaining two who had double vessel disease each had two significantly narrowed vein grafts (Table 2); the narrowing averaged $93.8 \%$ (range 75-100\%). In the 18 patients with either significantly diseased single or double vessels the maximal narrowing of the other coronary arteries averaged $27.9 \%$ (range $0-50 \%$ ).

Finally, in only two of the 46 patients did coronary angiography show more than one insignificantly stenosed segments per major coronary artery; these narrowings were respectively $40 \%$ and $50 \%$ and $50 \%$ and $50 \%$. No multiple lesions were found in the vein grafts.

COMPARISONS BETWEEN ANGIOCARDIOGRAPHY AND THE MAXIMAL ST/HR SLOPE

It was possible on 72 occasions to compare the maxi- mal ST/HR slope with the results of coronary arteriography. The results of the two tests-the maximal ST/HR slope and angiocardiography-were compared in 46 patients before operation and in 26 of these 46 patients six months after operation (Table 2).

\section{Preoperative data}

The number of significantly diseased coronary arteries was correctly detected by the maximal ST/HR slope in each of the 46 patients. The ranges of the maximal ST/HR slope for each of the three groups with single, double, and triple vessel disease, as shown by coronary arteriography, fell within the ranges previously reported in the series of 230 patients. ${ }^{3}$ There was no overlap between the ranges of the maximal ST/HR slope between the three groups of patients (Table 3), and the slopes were significantly different $(p<0.0005)$ from each other.

\section{Postoperative data}

At six months after operation the maximal ST/HR slope was compared with the results of angiocardiography in the 26 patients. Eight patients had no significant vessel disease, 16 single vessel disease, and two double vessel disease (Table 3).

For each of the three groups of patients the ranges of the maximal ST/HR slope (Table 3) were within the ranges previously reported in 230 patients with angina $^{3}$; there was no overlap in the ranges of the maximal ST/HR slopes between the eight patients with no significant vessel disease, 16 patients with single vessel disease, and the two patients with double vessel disease (Table 3). Thus the maximal ST/HR slope detected the presence or absence and the number of significantly diseased vessels in each of the 26 patients in the postoperative period.

Thus in a total of 72 tests performed before and after operation the maximal ST/HR slope accurately detected, without false results, the presence and the severity of coronary heart disease, as determined by angiocardiography in each of the 46 patients.

ASSESSMENT OF RESULTS OF AORTOCORONARY BYPASS

The efficacy of aortocoronary bypass in reducing the 
degree of severity of coronary heart disease was assessed (a) by comparing the exercise results with the results of angiocardiography at six months (that is, in 26 patients) and (b) briefly by considering the results of the exercise test in the light of the precise number of vessels bypassed (that is, in all the 46 patients immediately after operation).

Relevance of exercise test to the number of bypassed vessels and stenosed grafts

The changes in the results of angiocardiography and in the values of the maximal ST/HR slopes obtained before operation and six months afterwards were compared in each of the 26 patients (Figs. la and $1 \mathrm{~b}$ ).

When significantly diseased coronary arteries were bypassed by grafts which did not develop significant stenosis the reduction in the maximal ST/HR slope predicted the number of grafted coronary arteries
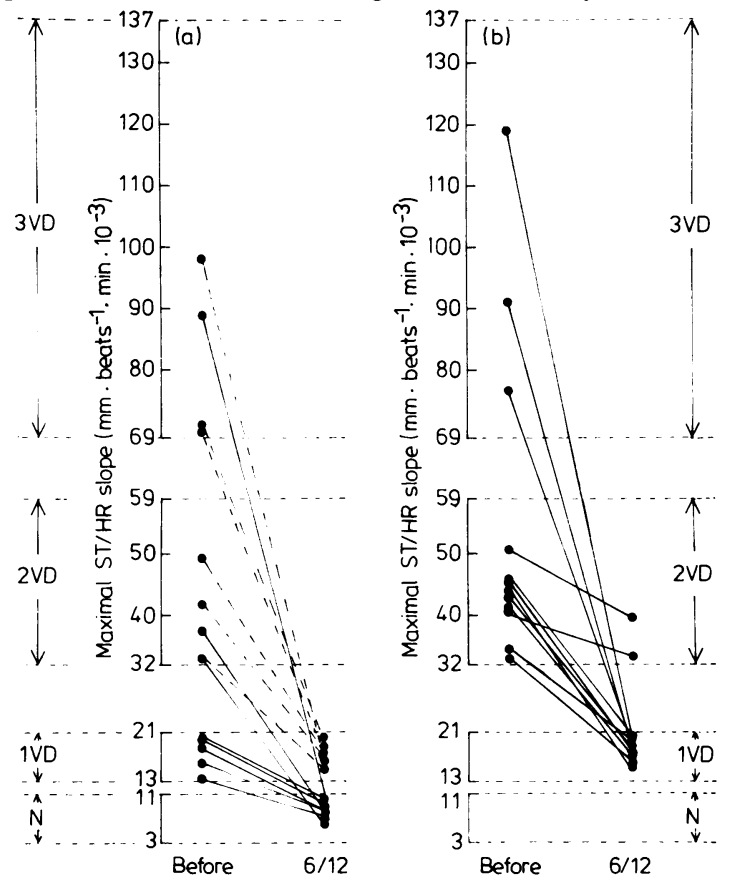

Fig. 1 Maximal ST/HR slope obtained before aortocoronary bypass and six months afterwards in each of 26 patients classified according to the state of vein grafts used to bypass significantly diseased coronary arteries: (a) patients with all vein grafts patent and $(b)$ patients with one or two vein grafts significantly stenosed. The limits of the ranges of the maximal ST/HR slopes previously shown in 230 patients are indicated: $N$, no significant vessel disease; IVD single vessel disease; $2 V D$, double vessel disease; $3 V D$, triple vessel disease.

Continuous lines indicate patients in whom all significantly stenosed coronary arteries were bypassed. Broken lines indicate patients in each of whom one significantly stenosed coronary artery could not be bypassed.
(Fig. 1a). The values of the maximal ST/HR slope changed from one range of significantly diseased vessels to another either with a smaller number of significantly diseased vessels, which remained ungrafted, or with no significant vessel disease. The reduction in the value of the slope precisely followed the number of the patent vein grafts. Of the 26 patients, 14 had patent vein grafts (Fig. 1a), 10 patients each had one significantly stenosed vein graft, and two patients each had two significantly stenosed vein grafts (Fig. 1b). Of the 14 patients with patent vein grafts, six had significantly stenosed coronary arteries which were not bypassed (Fig. 1a). Looking at the group of 26 patients as a whole the magnitude of reduction in the maximal ST/HR slope showed statistically significant correlation $(n=26 ; \quad r=0.80$; $p<0.001$ ) with the number of patent vein grafts used to bypass significantly diseased coronary arteries.

\section{Comparison of ST/HR slopes with details of bypassed} vessels

The values of the maximal ST/HR slopes before and three months after operation were compared in each of the 46 patients. In each patient the maximal ST/HR slope was lower after operation than before; at three months after operation the slopes of 12.75 $\mathrm{mm}$. beats ${ }^{-1}$. $\mathrm{min} .10^{-3}$ (mean; range 4.0-21.6) were significantly lower $(p<0.0005)$ than those of 50.55 $\mathrm{mm}$. beats ${ }^{-1}$. min. $10^{-3}$ (mean; range $13 \cdot 0-119 \cdot 1$ ) beforehand. There was a significant correlation $(r=0.76 ; \quad p<0.001)$ between the number of significantly diseased coronary arteries bypassed and the magnitude of reductions in the maximal ST/HR slope - that is, the reductions in the maximal ST/HR were greater the larger the number of bypassed significantly diseased coronary vessels.

\section{ASSESSMENT DURING POSTOPERATIVE PERIOD}

The value of the maximal ST/HR slope in the follow up (before six months) of changes in the severity of coronary heart disease was assessed in the 26 patients who had a repeat angiocardiography at six months after operation. The maximal ST/HR slopes obtained during the period from three months to six months after operation were considered in each of the 26 patients even though no angiocardiography was performed during the period. It was possible then to relate any changes to the subsequent findings of angiocardiography at six months (Figs. 2a and b).

Thus in the 14 patients without significant stenosis of the vein grafts (Fig. 2a) the changes in the maximal ST/HR slope over the period from three months to six months after operation were less than the equivalent of single vessel disease. The changes averaged -0.54 $\mathrm{mm}$. beats ${ }^{-1} \cdot \min .10^{-3}$ (range $-6 \cdot 00$ to $+4 \cdot 7$ ). Individual values of the maximal ST/HR slope for each 

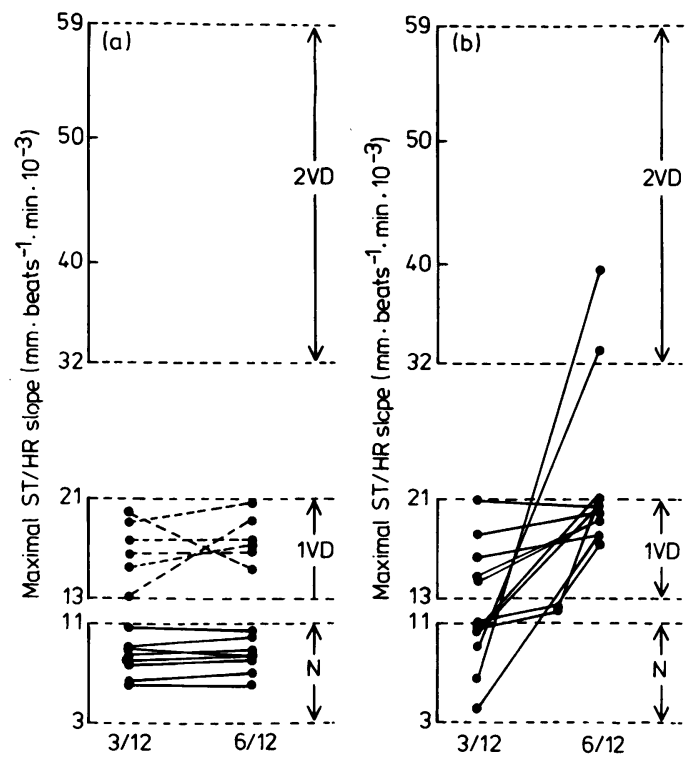

Fig. 2 Follow up data of the maximal ST/HR slope in each of the 26 patients shown in Fig. 1: (a) patients without significant stenosis of the vein grafts and (b) patients with significant stenosis of one of two vein grafts. The slopes were obtained three months (3/12) and six months (6/12) after aortocoronary bypass. The ranges of the maximal ST/HR slopes previously shown in 230 patients with angina are indicated: $N$, no significant vessel disease; IVD, single vessel disease; $2 V D$, double vessel disease.

Continuous lines indicate patients in whom all significantly stenosed coronary arteries were bypassed. Broken lines indicate patients in each of whom one significantly stenosed coronary artery could not be bypassed.

patient are shown in Fig. 2a; six of the 14 patients had significantly diseased coronary arteries which were not bypassed.

Twelve of the 26 patients had significant stenosis of at least one vein graft (Fig. 2b). In five of the 12 patients there was an increase in the maximal ST/HR slope over the period three months to six months after operation suggesting the development of single vessel disease; in each of these patients the maximal ST/HR slope increased from the range of no significant vessel disease to that of single vessel disease, and each patient was shown by angiocardiography at six months after operation to have significant stenosis of one vein graft. In these five patients the increase in the maximal ST/HR slope averaged $10.4 \mathrm{~mm}$. beats ${ }^{-1}$. min. $10^{-3}$ (range 6.6-13.0). In two of the 12 patients there was an increase in the maximal ST/HR slope which indicated the development of double vessel disease; in each of the two patients the maximal ST/HR slope increased from the range of no significant disease to that of double vessel disease (Fig. 2b), and each patient was shown by angiocardiography at six months after operation to have significant stenosis of two vein grafts. In the two patients the maximal ST/HR slope increased by 24.1 and $33.1 \mathrm{~mm}$. beats ${ }^{-1}$. min. $10^{-3}$ respectively. In the remaining five of the 12 patients the changes in the maximal ST/HR slope, which averaged $-2.36 \mathrm{~mm}$. beats ${ }^{-1}$. min. $10^{-3}$ (range -4.9 to $+1 \cdot 2$ ), were less than the equivalent of single vessel disease (Fig. 2b) suggesting that significant stenosis of the vein graft did not occur during the period between three months and six months after the operation-that is, significant graft stenosis occurred during the three months after the operation.

Repeated measurement of the maximal ST/HR slope, therefore, successfully detected the development of significant stenosis of vein grafts. In this context the follow up of the maximal ST/HR slope during the postoperative period in two of the 12 patients deserves a further mention. In the two patients (Fig. 2b) the maximal ST/HR slope was, in addition, obtained at the fifth month after operation; the values of the maximal ST/HR slope in these two patients were 12.0 and $12.1 \mathrm{~mm}$. beats ${ }^{-1}$. $\min .10^{-3}$ - that is, in a position between the limits of the ranges of no significant disease and single vessel disease, but no angiography was available at this time. When these two patients were examined by angiocardiography, however, the value of the maximal ST/HR slope showed an increase from a position between no significant disease and single vessel disease at five months to within the range of single vessel stenosis at six months after the operation (Fig. 2b).

\section{Discussion}

Many functional indices of the presence and severity of coronary heart disease have been used to assess the effects of aortocoronary bypass on the severity of the disease. These indices have involved the use of estimates of left ventricular function by cardiac catheterisation and angiocardiography ${ }^{5-9}$ and assessment of coronary heart disease or left ventricular function by radionuclide imaging ${ }^{10^{-16}}$ and exercise testing; the use of exercise tests is pertinent to the present study and will be considered in some detail.

\section{EXERCISE TESTS}

Many types of exercise tests, which include electrocardiographic recordings, have been investigated in attempts to provide indices of the presence and the severity of coronary heart disease ${ }^{17-25}$ Those tests have, however, been designed to rely on indices obtained at the end of the test which is in itself subjectively determined, and none has been shown to be accurate enough for use in detecting the presence or the severity of coronary heart disease in individual patients. ${ }^{317-25}$ In particular, after aortocoronary bypass patients are basically more likely to have single 
or double vessel disease than triple vessel disease. In such patients, those reported exercise tests would be inaccurate; a higher incidence of false negative results is obtained in patients with single or double vessel disease than in patients with triple vessel disease. ${ }^{202125}$ While reported exercise tests have indicated in groups of patients that aortocoronary bypass improves the blood supply to the myocardium, ${ }^{242627}$ an exercise test is required which is at least capable of detecting the presence and severity of coronary heart disease in every patient and then to provide an accurate and quantitative index of the degree of severity of coronary heart disease.

\section{MAXIMAL ST/HR SLOPE}

In the present study the maximal ST/HR slope was used as an index of the presence and the severity of coronary heart disease, because unlike all the other previously reported exercise tests it has been shown to fulfil the criteria for accuracy of detecting the disease in individual patients. For instance, firstly, in patients with anginal pain the maximal ST/HR slope accurately detected the presence or absence and the number of significantly diseased coronary arteries as shown by coronary arteriography; the details of 230 such patients have been published ${ }^{3}$; there were no false negative and no false positive results, and a definitive test result was obtained in every patientthat is there were no indeterminate test results. In a reproducibility study the maximal ST/HR slope was obtained twice within one week in each of 50 patients. ${ }^{3}$ The $95 \%$ tolerance limits, with $95 \%$ confidence intervals, of the difference between the two measurements were $\pm 1.9 \%$ indicating very little variability in the measurement; this small variability makes the index suitable for showing small changes in the degree of severity of coronary heart disease. Secondly, the accuracy of the slope in detecting the absence of significant coronary artery disease and the presence of single, double, or triple vessel disease was not influenced by factors such as the presence of hypokinesis of the left ventricle, the dominance of the left coronary system, a history of myocardial infarction, beta blockade, the value of the resting heart rate or blood pressure or their changes during exercise $^{1-3}$ Also there were no differences in the maximal ST/HR slope when measured before and after beta blockade in the same patient. ${ }^{4}$ Thirdly, in a trial in patients undergoing percutaneous luminal coronary angioplasty preliminary results have shown that the maximal ST/HR slope was lower after successful dilatation of the significantly narrowed coronary artery than before and that only a reduction of the narrowing from significant to insignificant resulted in a reduction in the value of the maximal ST/HR slope by the equivalent of "single coronary artery disease".28

\section{PRESENT STUDY}

That the maximal ST/HR slope is an accurate index of the presence and severity of coronary heart disease was further confirmed in the present study. Before aortocoronary bypass the maximal ST/HR slope detected with no false results the presence and the number of significantly diseased coronary arteries in each of the 46 patients. After operation again the maximal ST/HR slope detected, without false results, the absence of coronary heart disease and the presence of single or double vessel disease in each of the ' 26 patients examined. Therefore, in a total of 72 tests in the 46 patients the maximal ST/HR slope accurately detected, with no false results, the presence and severity of coronary heart disease as determined by angiocardiography.

Accepting the evidence previously reported ${ }^{3}$ and that in the present study, that the maximal ST/HR slope is an accurate index of the presence and severity of coronary heart disease, the present results show that aortocoronary bypass caused a reduction in the degree of severity of coronary heart disease. In each of the 46 patients the maximal ST/HR slope was lower after operation than before. Also the degree of reduction of the maximal ST/HR slope by the operation was determined by the number of narrowed coronary arteries which were successfully grafted. In particular, in any given patient successful grafting of a significantly diseased coronary artery was detected by the magnitude of reduction of the maximal ST/HR slope-that is, reduction in the degree of severity of myocardial ischaemia by a value equivalent to that of "single vessel disease".

In the patients in whom the grafts were patent and there was no significant disease in the other ungrafted coronary arteries aortocoronary bypass resulted in the restoration of adequate coronary blood supply to the myocardium; in eight patients the maximal ST/HR slopes, derived during the stress on the heart by exercise, showed values indicating insignificant coronary artery disease.

The findings of the present study have also shown that the measurement of the maximal ST/HR slope in patients who have undergone aortocoronary bypass provides quantitative means of assessing the changes in the severity of coronary heart disease during the period after operation. During the first six months after operation the present findings showed that the increase in the maximal ST/HR slope was associated with the occurrence of significant stenosis. For instance, firstly, in patients with an increase in the maximal ST/HR slope by the equivalent of "single vessel disease" angiocardiography showed the presence of significant stenosis in one vein graft (Fig. 2b). Secondly, in none of the 14 patients without significant stenosis of the vein graft did the changes in 
the maximal ST/HR slope during the period after operation exceed the equivalent of "single vessel disease." Finally, in the absence of angiographic information early after operation the present findings and those previously reported on the accuracy of the maximal ST/HR slope ${ }^{3}$ suggest that an increase in the value of the slope, by a magnitude which exceeds that of "single vessel disease," provides a quantitative estimate of the increase in the severity of coronary heart disease.

In the context of the present study it could be argued hypothetically that the degree of severity of myocardial ischaemia may possibly be influenced by several factors. As previously suggested, 23 changes in the size of the left ventricle and wall tension could, through changes in coronary perfusion pressure, influence coronary blood supply. In addition, anatomical variations of the coronary lesion-length and number-may influence coronary flow, although this influence is much smaller than that caused by narrowing of $>75 \%$ and in cases of multiple lesions flow is mainly determined by the lesion causing the greatest narrowing. ${ }^{329} 30$ Also spasm of the coronary vessels during exercise could contribute to the occurrence of myocardial ischaemia as previously suggested in a preliminary study. ${ }^{28}$ While in the present study patients with left ventricular dilatation-for example, through failure or valve disease-have been excluded and in none of the patients was coronary spasm suspected the present findings suggest that a degree of stenosis of $>75 \%$ in a major coronary vessel is of overriding importance relative to other variables; estimates of the exact contribution of any of these variables to the maximal ST/HR slope cannot be determined.

The findings from the repeated measurement of the maximal ST/HR slope also provide evidence which supports previously reported interpretations of the separation of ranges of the maximal ST/HR slope. Various studies in patients presenting with angina have found that the adjacent ranges of the maximal ST/HR slope, those correlating with insignificant, single, double, or triple vessel disease, have shown no overlap; the limits of adjacent ranges are quite separate. ${ }^{1-4}$ Such separation was attributed to the small variability (small tolerance limits) in the measurement of the maximal ST/HR slope plus the fact that the flow in the vessels is inversely related to the fourth power of the radius; a very small decrease in the luminal diameter in the range beyond $70-75 \%$ constriction results in dramatic sudden reduction in blood flow which is very much greater than that occurring when the increase in constriction is in the range from $0 \%$ to $70 \%$. Thus while insignificant coronary stenosis could lead to some degree of myocardial ischaemia, that caused by significant stenosis is much more severe. ${ }^{3}$ Little time, in terms of months, would be spent at or around this critical diameter; the progression from a small limitation to flow to a great limitation to flow would be short and therefore unlikely to have been appreciated in our previously reported studies. ${ }^{2}$ The design of the present study allowed repeated measurements of the slope at short intervals in patients, in some of whom the vein graft was subject to a relatively rapid process of narrowing. In the event, in two patients examined five months after operation the maximal ST/HR slope fell between the limits of no significant vessel disease and single vessel disease. At six months after operation - that is, within a month of the previous measurement-the maximal ST/HR slope became well within the limits of single vessel disease; in these two patients angiocardiography performed within the week after obtaining this slope showed significant stenosis of the vein graft. Such a course of events suggests that stenosis of the graft had developed over a short period of time, in terms of weeks rather than months, although this contention could be tested adequately in only a larger study designed for such a purpose.

The present findings show that the new test could be useful in patients who have undergone aortocoronary bypass because it has been estimated from prospective studies that only about $33-55 \%$ of such patients become asymptomatic and that only half of such patients have an uneventful course up to seven years after operation. ${ }^{31}$ Thus, as shown in this study, the maximal ST/HR slope would be useful in such patients reliably to detect the presence and severity of coronary heart disease whether it is caused by occlusion of the graft or significant disease of the coronary arteries. In addition, the present findings suggest that the serial measurement of maximal ST/HR slope, when taken in combination with the results of preoperative angiocardiography and the operative details, could provide information on significant graft stenosis early after operation. For instance, as shown in this study, the knowledge of absence of detectable narrowing of coronary vessels which remain ungrafted-the grafting, for example, of another coronary artery which postoperatively is accompanied either by a value of maximal ST/HR slope indicating significant vessel disease or by the increase of the maximal ST/HR slope from the range of insignificant vessel disease to significant vessel disease early after the operation-would indicate occlusion of the vein graft. It has been shown that there is in every patient a small but definite risk of occlusion of the vein graft; for example, data from the Montreal Heart Institute have shown that $7-15 \%$ of vein grafts become occluded within one month and 10-25\% become occluded within 12 months. After the first postoperative year the attrition rate of grafts is about $2 \cdot 2 \%$ per year. ${ }^{32-34}$

In conclusion, the maximal ST/HR slope obtained 
non-invasively can be used quantitatively to indicate an improvement in the blood supply to the myocardium in patients after aortocoronary bypass surgery and the slope can be reliably used in patients who have undergone operation to detect graft occlusion and deterioration in the degree of severity of coronary heart disease.

MMK was supported by the British Heart Foundation, and we thank them for their financial support.

\section{References}

1 Elamin MS, Mary DASG, Smith DR, Linden RJ. Prediction of severity of coronary artery disease using slope of submaximal ST segment/heart rate relationship. Cardiovasc Res 1980; 14: 681-91.

2 Elamin MS, Boyle RM, Kardash MM, et al. Accurate detection of coronary heart disease by a new exercise test. $\mathrm{Br}$ Heart $\mathcal{F}$ 1982; 48: 311-20.

3 Linden RJ, Mary DASG. Limitation and reliability of exercise electrocardiography tests in coronary heart disease. Cardiooasc Res 1982; 16: 675-710.

4 Kardash MM, Boyle RM, Elamin MS, Stoker JB, Mary DASG, Linden RJ. Detection of severity of coronary artery disease by the ST segment/heart rate relationship in patients on beta-blocker therapy. Cardiooasc Res 1982; 16: 508-15.

5 Shepherd RL, Itscoitz SB, Glancy DL, et al. Deterioration of myocardial function following aorto-coronary bypass operation. Circulation 1974; 49: 467-75.

6 Wolf NM, Kreulen TH, Bove AA, et al. Left ventricular function following coronary bypass surgery. Circulation 1978; 58: 63-70.

7 Chatterjee K, Swan HJC, Parmely WW, Sustaita H, Marcus HS, Matloff J. Influence of direct myocardial revascularization on left ventricular asynergy and function in patients with coronary heart disease. Circulation 1973; 47: 276-86.

8 Bristow JD, Rahimtoola SH. Effects of coronary bypass surgery on left ventricular function. In: Rahimtoola SH, ed. Coromary bypass surgery. Philadelphia: FA Davis, 1977: 97.

9 Serruys PW, Rousseau MF, Cosyns J, Ponlot R, Brasseur LA, Detry J-MR. Haemodynamics during maximal exercise after coronary bypass surgery. $\mathrm{Br}$ Hear $\mathcal{f}$ 1978; 40: 1205-15.

10 Epstein SE. Implications of probability analysis on the strategy used for non-invasive detection of coronary artery disease. $A m \mathcal{F}$ Cardiol 1980; 46: 491-9.

11 Strauss HW, Pitt B. Evaluation of cardiac function and structure with radioactive tracer techniques. Circulation 1978; 57: 645-54.

12 Pfisterer M, Emmenegger H, Schmitt HE, et al. Accuracy of serial myocardial perfusion scintigraphy with thallium-201 for prediction of graft patency early and late after coronary artery bypass surgery. A controlled prespective study. Circulation 1982; 66: 1017-24.

13 Kolibash AJ, Call TD, Bush CA, Tetalman MR, Lewis RP. Myocardial perfusion as an indicator of graft patency after coronary artery bypass surgery. Circulation 1980; 61: 882-7.

14 Massie B, Botvinick EH, Brundage BH, Greenberg B, Shames D, Gelberg $H$. Relationship of regional myocardial perfusion to segmental wall motion. A physiologic basis for understanding the presence and reversibility of asynergy. Circulation 1978; 58: $1154-63$.

15 Kent KM, Borer JS, Green MV, et al. Effects of coronary artery bypass on global and regional left ventricular function during exercise. $N$ Engl f Med 1978; 298: 1434-9.

$16 \mathrm{Lim}$ YL, Kalff V, Kelly MJ, et al. Radionuclide angiographic assessment of global and segmental left ventricular function at rest and during exercise after coronary artery bypass graft surgery. Circulation 1982; 66: 972-9.

17 Fortuin NJ, Weiss JL. Exercise stress testing. Circulation 1977; 56: 699-712.

18 Ellestad MH. Stress testing. Principles and practice. Philadelphia: Davis, 1980.

19 Simoons ML, Block P. Towand the optimal lead system and optimal criteria for exercise electrocardiography. Am f Cardiol 1981; 47: 1366-74.

20 Chaitman BR, Waters DD, Bourassa MG, Tubau JF, Wagniart $P$, Ferguson RJ. The importance of clinical subsets in interpreting maximal treadmill exercise test results. The role of multi-lead ECG systems. Circulation 1979; 59: 560-70.

21 Baron DW, Poole-Wilson PA, Rickards AF. Maximal 12-lead exercise testing for prediction of severity of coronary disease. Eur 7 Cardiol 1980; $11: 259-67$.

22 Fox KM, England D, Jonathan A, Selwyn AP. Precordial surface mapping of the exercise ecg. Br f Hosp Med 1982; 27: 291-9.

23 Simoons ML, Hugenholtz PG, Ascoop CA, Distelbrink CA, De Land PA, Vinke RVM. Quantitation of exercise electrocardiography. Circulation 1981; 63: 471-5.

24 Talbot S, Kilpatrick D, Oakley D. Coronary artery bypass surgery. Assessment of graft patency by exercise testing. Eur Hean $\mathcal{F}$ 1982; 3: 348-52.

25 Raffo JA, Luksic IY, Kappagoda CT. Diagnostic value of routine exercise testing in hospital patients with angina pectoris. $\mathrm{Br}$ Med f 1979; ii: 295-7.

26 Knoebel SB, McHenry PL, Phillips JF, Lowe DK. The effect of aortocoronary bypass grafts on myocardial blood flow reserve and treadmill exercise tolerance. Circulation 1974; 50: 685-93.

27 Luksic IY, Raffo JA, Mary DASG, Watson DA, Deverall PB, Linden RJ. Use of exercise tests in the assessment of functional result of aortocoronary bypass surgery. Thorax 1981; 36: 428-34.

28 Silverton NP, Elamin MS, Ionescu MI, Smith DR, Whitaker W. Quantitative evaluation of the outcome of percutaneous transluminal coronary angioplasty. Clin Sci 1982; 63: 50P.

29 Sabbah HN, Stein PD. Hemodynamics of multiple versus single 50 percent coronary arterial stenoses. Am $\mathcal{J}$ Cardiol 1982; 50: 276-80.

30 Robbins SL, Bentov I. The kinetics of viscous flow in a model vessel. Effect of stenoses of varying size, shape and length. $L a b$ Invest 1967; 16: 864-74.

31 Rahimtoola SH. Coronary bypass surgery for chronic angina1981. A perspective. Circulation 1982; 65: 225-41.

32 Bourassa MG, Campeau L, Lesperance J. Effects of bypass surgery on the coronary circulation: incidence and effects of vein graft occlusion. In: Rahimtoola SH, ed. Coronary bypass surgery. Philadelphia: FA Davis, 1977: 107.

33 Campeau L, Lesperance J, Corbara F, Hermann J, Grondin CM, Bourassa MG. Aorto-coronary saphenous vein bypass graft changes 5 to 7 years after surgery. Circulation 1978; 58 (suppl I): $170-5$.

34 Bourassa MG, Campeau L, Lesperance J, Grondin CM. Changes in grafts and coronary arteries after saphenous vein aortocoronary bypass surgery: results of repeated angiography. Circulation 1982; 65 (suppl II): 90-7. 